\title{
Fault Current Characterisation in VSC-based HVDC Systems
}

\author{
Sul Ademi*, Dimitrios Tzelepis*, Adam Dyśko*, Sankara Subramanian ${ }^{\dagger}, \mathrm{Hengxu} \mathrm{Ha}^{\dagger}$ \\ *University of Strathclyde, Glasgow, UK, \\ sul.ademi@strath.ac.uk,dimitrios.tzelepis@strath.ac.uk,a.dysko@strath.ac.uk \\ ${ }^{\dagger}$ Alstom Grid Technology Centre, Stafford, UK, \\ sankara.subramanian@alstom.com, hengxu.ha@alstom.com
}

\begin{abstract}
Keywords-Fault characterisation, fault location, voltage-source converter (VSC), DC fault protection, high-voltage directcurrent (HVDC)
\end{abstract}

\begin{abstract}
The DC-side line faults in high-voltage direct-current (HVDC) systems utilising voltage-source converters (VSCs) are a major concern for multi-terminal HVDC systems in which complete isolation of the faulted system is not a viable option. A number of challenges are posed by both pole-to-pole and pole-to-ground faults including the presence of very fast and high amplitude discharge current from the DC-link capacitance, the lack of suitable DC current breaking devices, and the lack of highly discriminative fault detection techniques. Therefore, faults occurring along the interconnecting DC cables are likely to threaten system operation. In order to better understand the system under such faults, this paper analyses the behaviour of HVDC systems energised by the conventional two-level VSC. This investigation provides a systematic evaluation of the nature of a DC fault in HVDC systems during a permanent poleto-pole and pole-to-ground fault taking into consideration a number of influencing parameters including fault position, fault resistance and other operational conditions. To quantify these dependencies on DC voltage and current characteristics a systematic simulation study is undertaken in which the natural responses of the HVDC networks transients during DC side faults are examined. The outcome of this paper lies the necessary knowledge foundation for developing future DC protection methods.
\end{abstract}

\section{Introduction}

High-voltage direct-current (HVDC) systems employing voltage-source converters (VSCs) have been accepted as a feasible solution to implement efficient grid integration and power transmission for large-scale renewable generations over long distances [1]-[3]. The feasibility of future multiterminal direct-current (MTDC) networks has attracted vast interest in the recent years [4], the attraction of such systems is due to the application of high-power VSC for large scale offshore wind farm integration to onshore grids [1], [5], where a reliable DC network is a prerequisite. However, before such a system can become a reality, various technical challenges need to be overcome to ensure safe and stable system operation on a large scale level.
One of the most important and challenging issues yet to be addressed is the protection of the system under DC fault conditions [6]. Fault vulnerability and protection are major issues that constrain the development of VSC-based DC networks [7], particularly in high-power scenarios and with more than two terminals. The development of VSC-based DC networks is constrained by the lack of operational experience, lack of maturation of appropriate protection devices and the lack of appropriate fault analysis which needs further investigation [8]. Current protection schemes for point-to-point VSC-HVDC systems involve disconnection of the faulted line via $\mathrm{AC}$ circuit breakers, isolating the $\mathrm{DC}$ system in its entirety. However, this is not a viable option for MTDC systems, due to the large transmission capacities involved, therefore it becomes necessary to quickly and reliably detect and isolate only the faulted line, thus protecting the sensitive power electronics of the converter, while ensuring security of supply is maintained [6], [9].

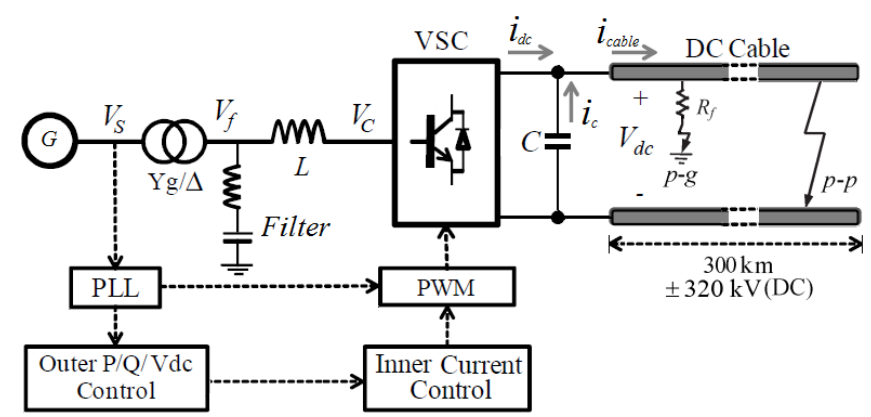

Figure 1: VSC-HVDC system with two-level topology.

Isolation of a faulted DC line has been proposed by utilisation of DC circuit breakers (DCCBs) [10]-[14]. However, the development of such breakers for high-voltage applications has presented a problem for years since, unlike in AC systems, there is no natural current zero within DC systems, therefore such a breaker would have to force the current to zero and dissipate the energy stored in the system inductance [15]-[17]. Cable faults do occur more frequently compared to other parts of the system. The most common reason for a cable fault is insulation deterioration and breakdown. There can be several causes [4]: physical damage, environmental and electrical stress, or cable ageing. In [18] the influence of DC faults on DC networks at transmission and distribution levels are analysed.

The VSC-based transmission systems are robust to the fault conditions on $\mathrm{AC}$-side, however, the most critical challenge 
for VSC-HVDC systems lies in its response to DC-cable faults as shown in Figure 1. The DC capacitor discharges very high rapidly increasing current during the DC fault, causing serious damage on the DC side of the converter station [19]. Unfortunately, the classical VSCs are defenceless against DC-side faults since their freewheeling diodes function as an uncontrolled rectifier bridge and feed the DC fault [18], [20], [21], even if the semiconductor devices are turned off. During the DC fault, the AC-side current contribution into the DC fault passes through the freewheeling diodes and as a result, the diodes are quickly damaged due to high fault current. Some analysis of pole-to-pole and poleto-ground faults based on VSC systems has been carried out in [18], [22]. The pole-to-pole faults are classified as severe but less likely to happen, on the contrary, the pole-to-ground faults are the most likely fault scenario but generally less harmful. A further in-depth analysis into the converters behaviour during such an occurrence could prove advantageous in improving general understanding of system operation, and fault behaviour in particular.

Consequently, this paper provides detailed analysis on the behaviour of a VSC-HVDC converter during the DC poleto-pole and pole-to-ground faults for two-level VSC-based systems with a range of fault resistances, distances, and operational conditions. Furthermore, it addresses DC fault characteristics and their transients. The paper is organised as follows. In Section 2, the DC-cable pole-to-pole solid faults are analysed taking into account the natural behaviour of such faults; Section 3, investigates the DC-cable pole-toground faults under varying resistances; and, finally, Section 4 , recaps the main conclusions of the paper.

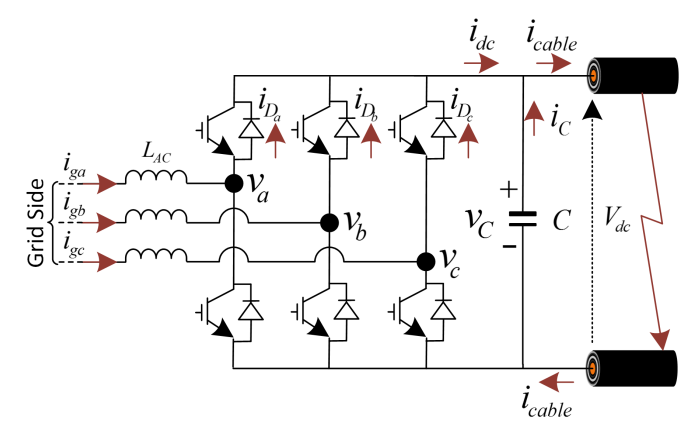

Figure 2: VSC with cable pole-to-pole fault state.

\section{VSC-HVDC Pole-to-Pole Fault Analysis}

This section details the DC-side performance during poleto-pole faults in VSC-based DC systems. According to [18], DC bus faults are the same as DC-cable faults and different in protection coordination strategy merely because of possible complex structured multi-terminal connection. The theoretical solution of the non-linear system that represents the faulted network can be defined by different stages which could assist in understanding system response. The characteristics of the DC fault current response are analysed for various fault locations. The simulation results are developed utilising Matlab-Simulink ${ }^{\circledR}$ toolbox, distributed parameters line model and simulation system parameters introduced in Table 3 , in order to characterise and capture such natural fault responses.

\subsection{VSC Cable Pole-to-Pole Fault Analysis}

A DC pole-to-pole fault is the most serious condition for VSC-HVDC system. Regardless of the fault position along the DC-cable, a pole-to-pole fault can be represented by the schematic shown in Figure 2. After inception the DC fault current goes through three different stages [18]:

- Stage 1. Capacitor discharge stage: During this stage, the DC-link capacitor starts discharging rapidly, thus the system experiences a DC voltage collapse Figure 3(a). The discharge current has a high peak and decays with time (natural response).

- Stage 2. Diode freewheeling stage: This stage is initiated when the DC fault commutates to the converter freewheeling diodes as shown in Figure 3(b). The DC-link voltage reaches zero and the cable inductance drives the current around the freewheeling path where each converter leg carries one-third of the fault current $\left(i_{D_{a}}=i_{\text {cable }} / 3\right.$ ) [18]. The initial diode currents are high which may damage them, then the current decays with time.

- Stage 3. Grid-side current feeding stage: During this stage, the DC-link capacitor and cable inductor have a forced current source response, where the grid current contribution into the DC fault $\left(i_{G r i d}\right)$ is the sum of the positive three-phase fault currents as shown in Figure 3(c).

\subsection{Simulation Results for Pole-to-Pole Faults}

In an event of pole-to-pole fault the DC-link voltage drops to zero, as further illustrated by the positive and negative pole voltages in Figure 4. The corresponding system DC currents are shown in Figure 5, in which, the three stages, as defined in section 2.1 are indicated. Stage 1, the capacitor discharge indicates the immediate effect which introduces the high DC current surges into the cable within the first few ms. In keeping with the theoretical analysis, stage 2 begins right after the DC-link voltage drops to zero and therefore the DClink capacitor is fully discharged. Finally, stage 3 indicates the steady state fault current feeding through from the AC side and at this point the capacitor will try to re-charge again, as shown in Figure 4.

Location of the fault is shown to have a significant influence on the system response during pole-to-pole faults. Results show that as the fault location moves further away from the converter, the response becomes slower which can be seen on both DC voltages and currents. Such behaviour is apparent from Figure 5. A closer depiction of this effect is shown in Figure 6 which illustrates the fault stages in their entirety. It can be observed that with increasing distance to fault the peak current is reduced as well as initial rate of change of current leading to longer current flow periods. This is expected, since the values of resistance and reactance in the fault loop increase proportionally with distance. Higher values of $\mathrm{L}$ limit the rate of change of current, while higher values of $\mathrm{R}$ reduce the value of the peak. The initial rates of change of current at different distances are depicted in Table 1. Figure 5 verifies this effect as the falling behaviour of the peak-values can be clearly observed. 


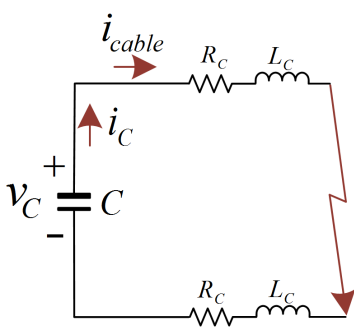

(a) Capacitor discharge

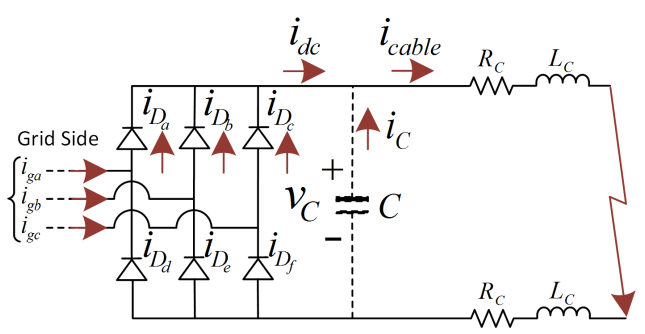

(b) Diode freewheeling

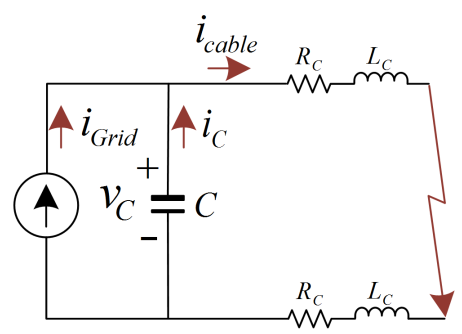

(c) Grid current feeding

Figure 3: VSC-HVDC cable pole-to-pole fault.

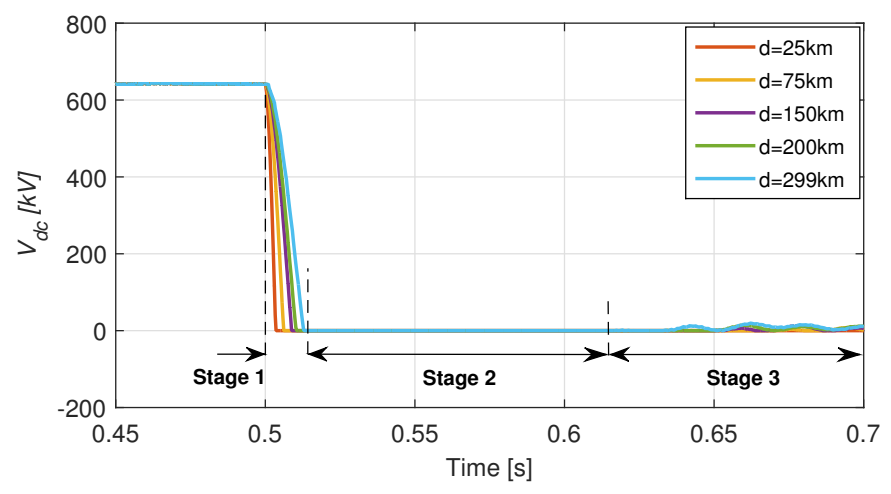

(a) DC-link voltage

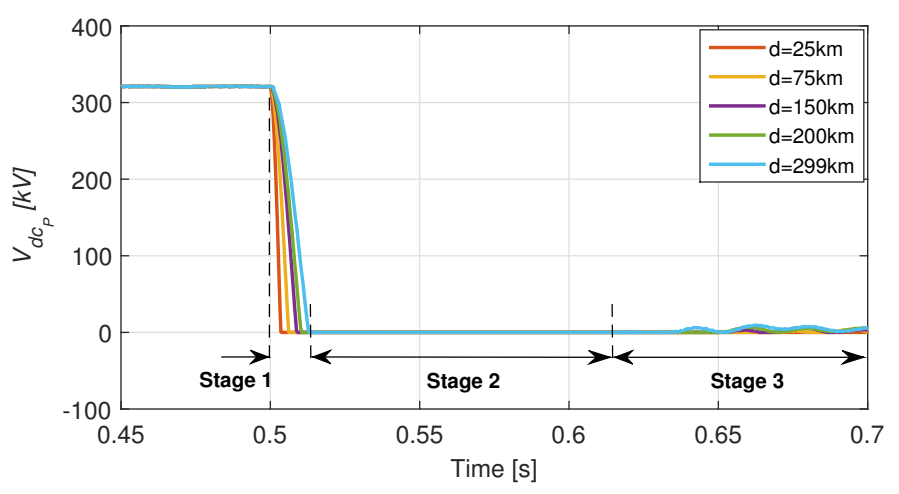

(b) DC-link (+) voltage

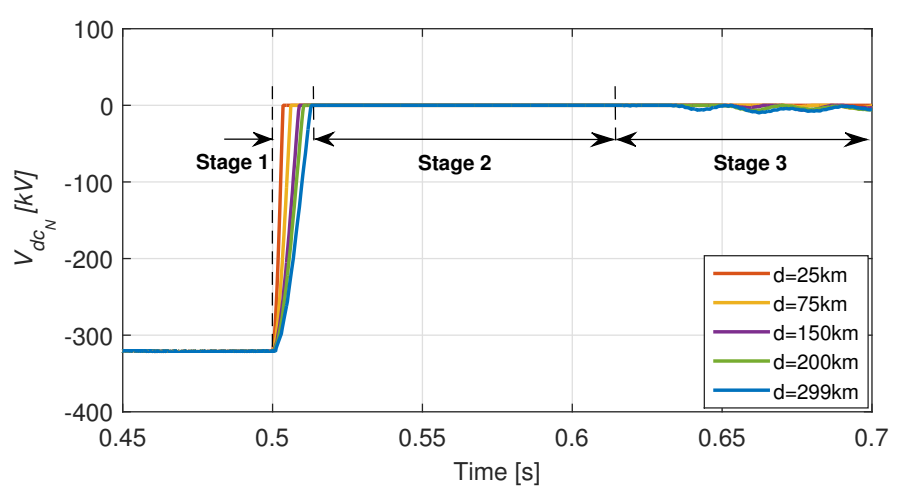

(c) DC-link (-) voltage

Figure 4: VSC cable pole-to-pole fault and stage definition at different fault locations.

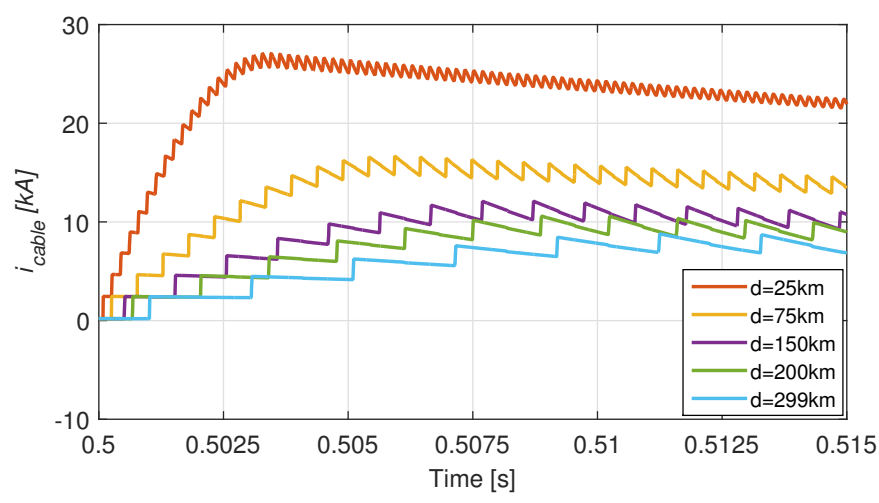

(a) Cable current

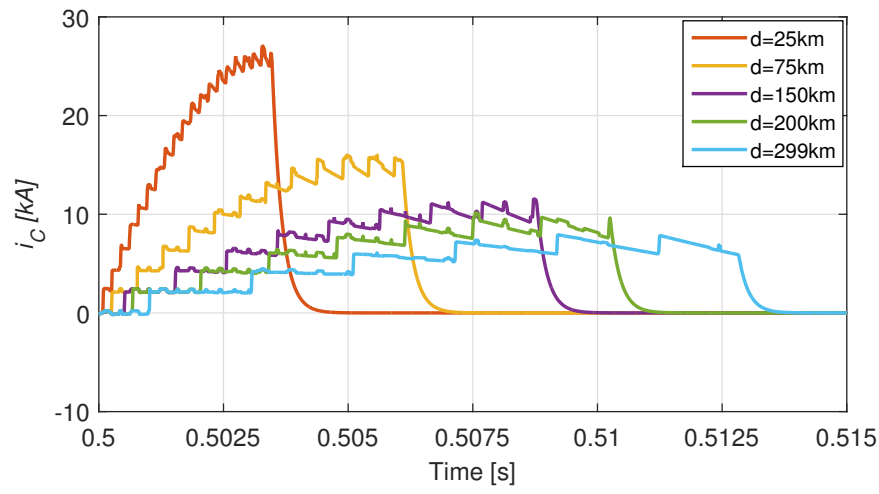

(b) Capacitor current

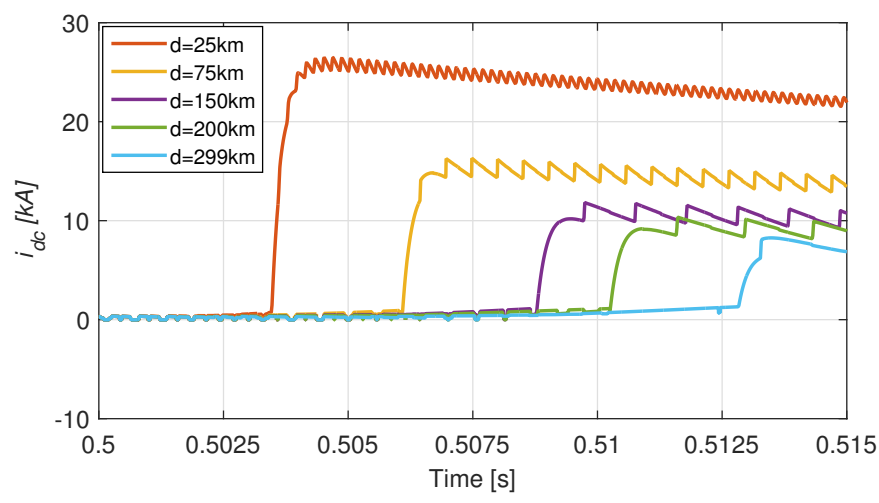

(c) VSC feeding current

Figure 5: Simulation waveforms of VSC with pole-to-pole fault. 


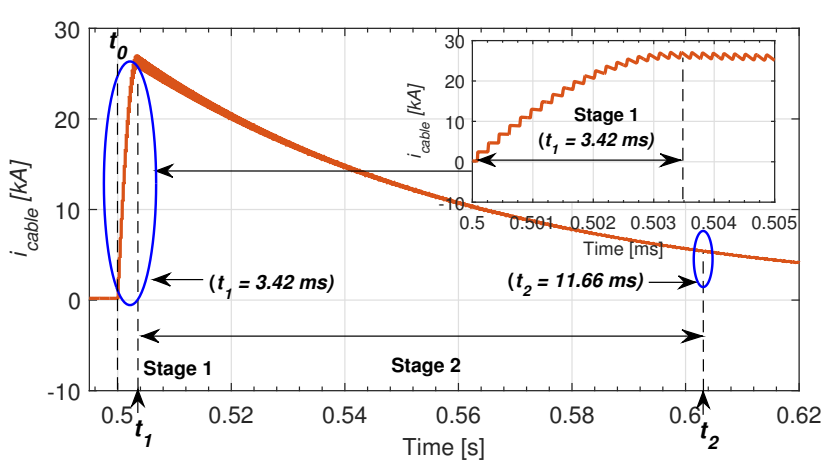

(a) Cable current

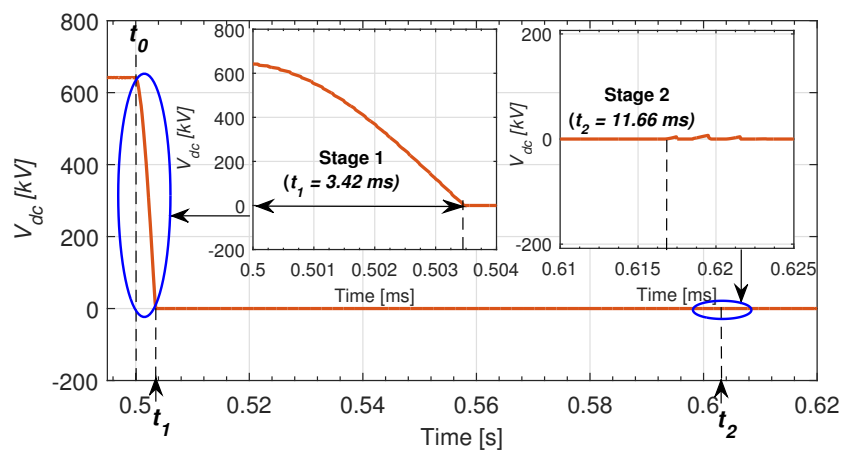

(b) DC-link capacitor voltage

Figure 6: Stage one and two illustration for pole-to-pole fault with distance to fault $25 \mathrm{~km}$.

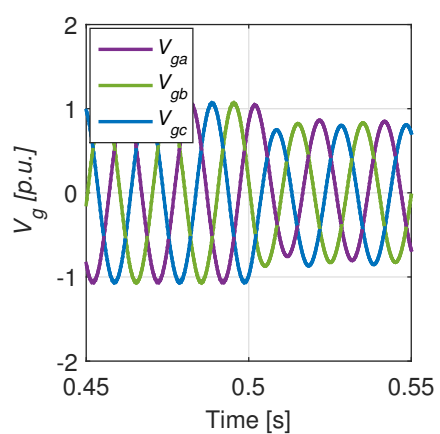

(a) Grid-side voltages

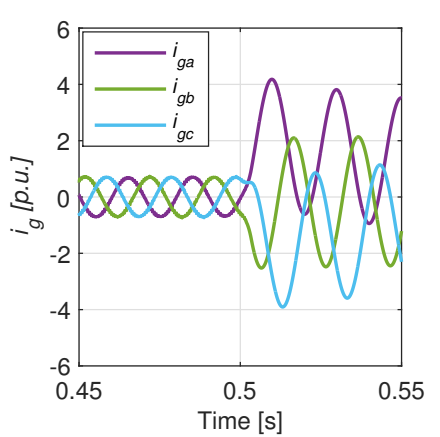

(b) Grid-side currents
Figure 7: VSC-HVDC cable pole-to-pole fault.

Figure 7 illustrates the AC current circulating through the diode rectifiers and DC cable. Such operation affects both the grid-side voltages $\left(v_{g_{a b c}}\right)$ and grid-side currents $\left(i_{G r i d_{a b c}}\right)$. In particular, a voltage depression of around $20 \%$ is observed, while the AC-side current reaches an initial value of $\approx 4.0$ p.u. (during stage 1 ) and then falls to $\approx 2.0$ p.u. during the steady state (stage 3 ). From the protection point of view the fault should be contained before the capacitor is fully discharged (i.e. total system collapse). What is worth noting here is the travelling wave propagation observed in Figure 5(a). Results show that travelling wave effect is present and its duration seems to increase, as the fault distance increases (which corroborates with the theory).

\begin{tabular}{||l||c||}
\hline \hline Distance & Peak Current [kA] \\
\hline \hline $25 \mathrm{~km}$ & 27.08 \\
\hline $75 \mathrm{~km}$ & 16.68 \\
\hline $150 \mathrm{~km}$ & 12.10 \\
\hline $200 \mathrm{~km}$ & 10.58 \\
\hline $299 \mathrm{~km}$ & 8.79 \\
\hline
\end{tabular}

Table 1: VSC pole-to-pole fault peak currents Figure 5(a).

\section{VSC Cable Pole-to-Ground Faults}

This section details the DC-side performance during poleto-ground faults in VSC-based DC systems. Pole-to-ground faults are more common, while less harmful for the system in comparison to pole-to-pole faults. Such faults are triggered when the insulation of the cable breaks and the live conductor touches the ground directly or through other conducting paths [23], [24]. The severity of pole-to-ground fault in a conventional VSC-HVDC system depends on the fault impedance, grounding configuration [25] and the HVDC topology of the DC system. The DC-link capacitors discharge through the pathways constructed by the grounding loop of the DC capacitors to the ground fault, making it much easier to cause a large discharge current flow.

\subsection{VSC Cable Pole-to-Ground Fault Analysis}

The fault analysis presented here takes into consideration the neutral-ground link of the transformer and the DC-link midpoint as shown in Figure 8. The DC-link grounding at the mid point is used in practice to reduce imbalance between the positive and negative voltages and currents. The stage of diode freewheeling effect is completely eliminated in pole-toground faults [26]. Furthermore, the ground fault resistance cannot be ignored since its value can vary significantly. Fault resistance is therefore integrated into the short circuit analysis and it plays a significant role in the system response. The total system impedance is expressed by Equation (1) which in turn can reduce the current flowing into the cable. Such faults can therefore be analyses in two stages:

- Stage 1. Capacitor discharge stage: During this stage, the DC-link voltage will not drop to zero, so no freewheeling diode conduction occurs as shown in Figure 9(a), (unlike the freewheeling phase during pole-to-pole faults) [18].

- Stage 2. Grid-side current feeding stage: This stage takes place after the capacitor discharge when its voltage drops close to zero as illustrated schematically in Figure 9(b).

The equivalent impedance $|Z|$ can be determined as:

$$
Z=\left(R_{f}+R+j \omega_{s} L\right) \|\left(1 / j \omega_{s} C\right)+j \omega_{s} L_{\text {choke }}=|Z| \angle \theta
$$

While the cable current $i_{\text {cable }}$ 'steady-state fault current' is determined by taking into consideration the diode current expressed by Equation (2):

$$
i_{D_{a}}=i_{g_{a}}=i_{D_{b}}=i_{D_{c}}=\frac{V_{g a}}{|Z|}=\frac{V_{g a} \angle \alpha}{|Z| \angle \theta}
$$




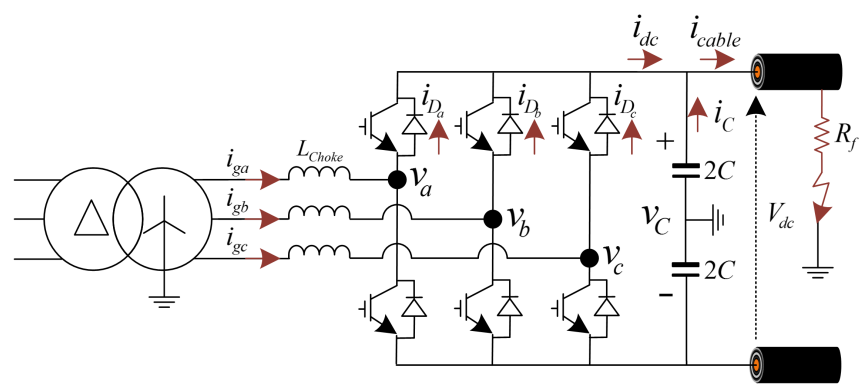

Figure 8: VSC with cable pole-to-ground fault state.

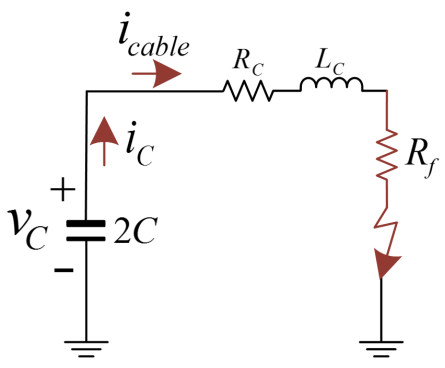

(a) Capacitor discharge

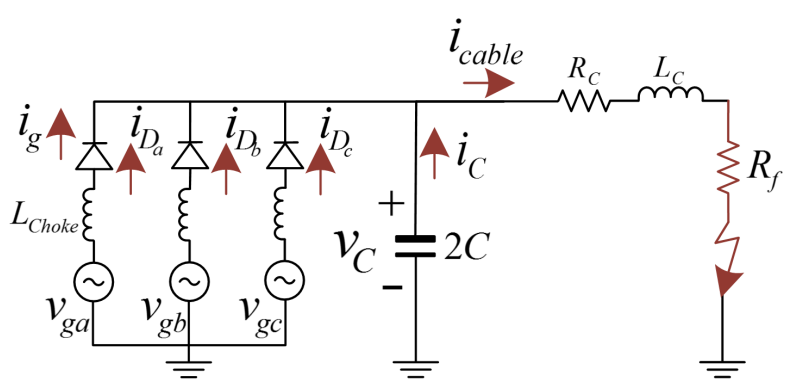

(b) Grid current infeed

Figure 9: Representation for VSC cable pole-to-ground fault.

\subsection{Simulation Results for Pole-to-Ground Faults}

Pole-to-ground faults have a different impact on the system behaviour than pole-to-pole faults. As mentioned before the DC-link voltage does not drop to zero, but after a transient it recovers back to an acceptable level. In fact the system DC voltage operation switches from symmetrical to asymmetrical, where the faulty pole voltage $\left(V_{d c_{P}}\right)$ collapses towards zero as in Figure 10(a), and the healthy pole voltage $\left(V_{d c_{N}}\right)$ 'jumps' towards $640 \mathrm{kV}$ (2 p.u.) as Figure 10(b) illustrates. The capacitor voltage drops to a new steady state, while the inductor current experiences a large transient. In particular, as Figures 10 and 11 depict, its maximum values vary between 2 and 4 p.u. (refer to Table 2) depending on the value of ground fault resistance. The authors determined that the current peak values for fault location of $299 \mathrm{~km}$ were similar to the results shown in Figures 10 and 11, hence, they are omitted here. Furthermore, Figures 10 and 11, indicate a duration in which the waves travel through the line (till the fault point) and reflected back to the measurement point (rectifier side). Consequently, the higher the fault distance, the greater the wave duration. Such signal information can be a very useful indicator for both protection and fault location schemes.

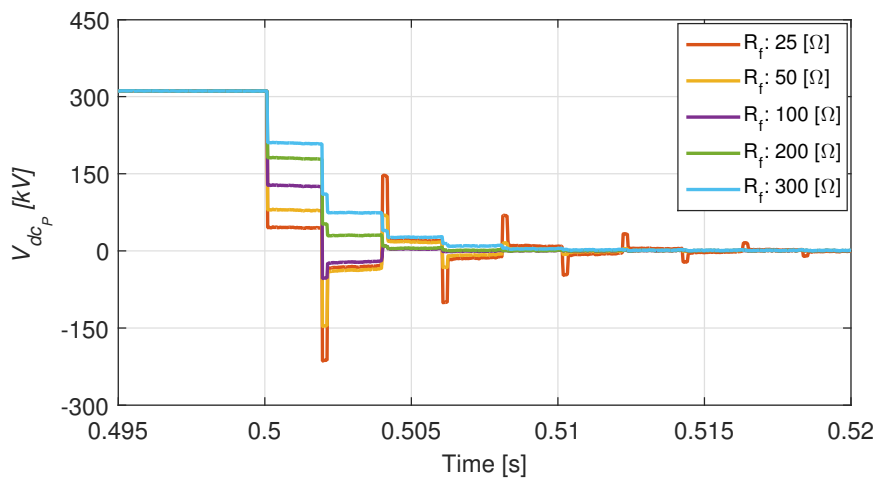

(a) DC-link (+) voltage

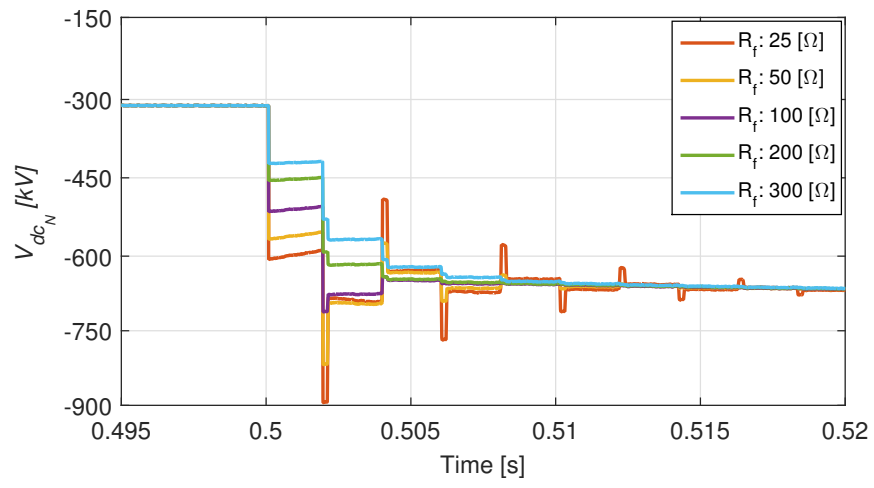

(b) DC-link (-) voltage

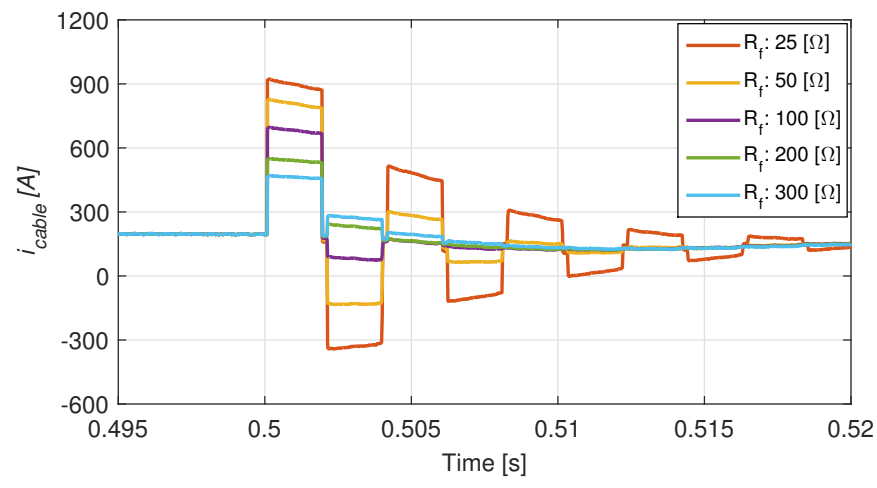

(c) Cable current

Figure 10: VSC cable pole-to-ground fault under varying fault resistances with distance to fault $25 \mathrm{~km}$.

\begin{tabular}{||c||c||c||c||c||c||}
\hline \hline Dist. & $\mathbf{2 5} \Omega$ & $\mathbf{5 0} \Omega$ & $\mathbf{1 0 0} \Omega$ & $\mathbf{2 0 0} \Omega$ & $\mathbf{3 0 0} \Omega$ \\
\hline \hline $\mathbf{2 5 k m}$ & 923.02 & 828.15 & 697.30 & 550.52 & 470.80 \\
\hline $\mathbf{1 5 0 k m}$ & 918.85 & 824.55 & 694.48 & 548.53 & 468.68 \\
\hline $\mathbf{2 9 9 k m}$ & 911.26 & 817.67 & 688.55 & 543.70 & 464.43 \\
\hline \hline
\end{tabular}

Table 2: VSC cable pole-to-ground fault peak currents corresponding to Figure 10(c), Figure 11(c) and 299km distance.

The AC current feeding stage is then reached, where the cable current operates in steady state mode. The value of the current natural response can be defined by the equivalent impedance formed within the fault current loop which can be expressed by Equation (2). 


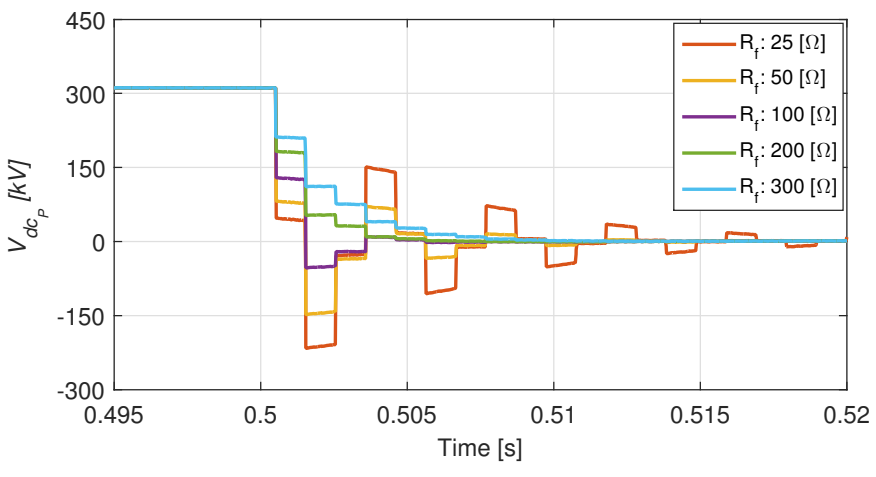

(a) DC-link (+) voltage

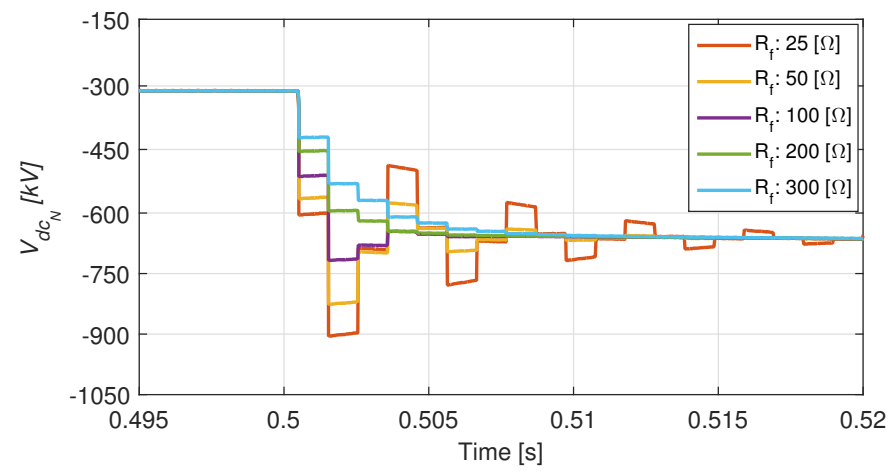

(b) DC-link (-) voltage

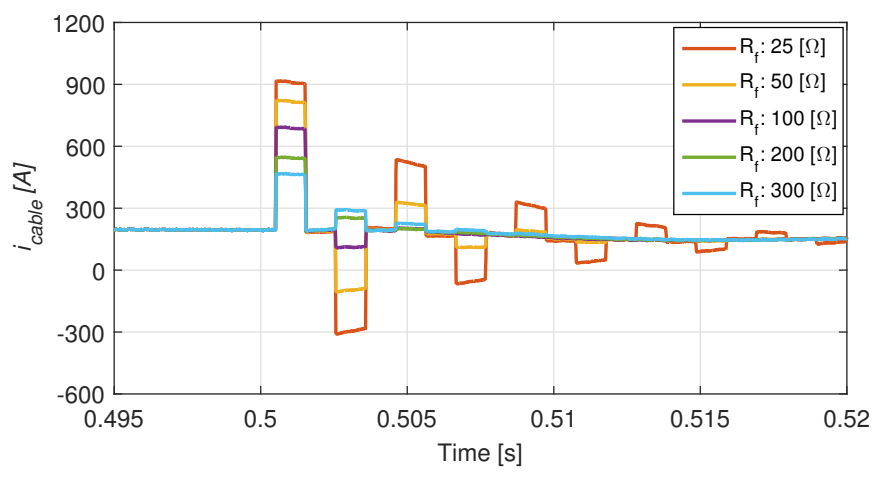

(c) Cable current

Figure 11: VSC cable pole-to-ground fault under varying fault resistances with distance to fault $150 \mathrm{~km}$.

\section{Conclusions}

DC system protection for high-power penetration is a prominent area of investigation due to the potential development of multi-terminal DC grids. This paper systematically analyses the behaviour of the point-to-point VSC-based DC system under most critical DC pole-to-pole and pole-toground faults, outlining system behaviour depending on the earthing configuration considered. Fault current responses are simulated to identify and quantify the worst case scenario cases as well as distinct fault current features leading to the development of a reliable protection method.

- Pole-to-pole faults are considered as more severe due to the fact that they force the system to collapse, but

\begin{tabular}{||l||l||}
\hline \hline Parameter & Value \\
\hline \hline DC Line Resistance $\left[R_{D C}\right]$ & $15.0 \mathrm{~m} \Omega / \mathrm{km}$ \\
\hline DC Line Inductance $\left[L_{D C}\right]$ & $0.96 \mathrm{mH} / \mathrm{km}$ \\
\hline DC Line Capacitance $\left[C_{D C}\right]$ & $0.012 \mu \mathrm{F} / \mathrm{km}$ \\
\hline DC Line Length & $300 \mathrm{~km}$ \\
\hline \hline \hline AC Voltage $(\mathrm{L}-\mathrm{L}$, RMS $)$ & $400 \mathrm{kV}$ \\
\hline AC Frequency & $50 \mathrm{~Hz}$ \\
\hline X/R Ratio of AC Network & 10 \\
\hline AC Short Circuit Level & $2 \mathrm{GVA}$ \\
\hline Interfacing Transformer Voltages & $400 / 330 \mathrm{kV}$ \\
\hline \hline \hline DC Voltage $\left[V_{d c}\right]$ & $\pm 320 \mathrm{kV}$ \\
\hline DC-Link Capacitance $\left[C_{d c}\right]$ & $100 \mu \mathrm{F}$ \\
\hline IGBT $\left[R_{o n}\right]$ & $1 \mathrm{~m} \Omega$ \\
\hline Choke Inductance $\left[L_{C h o k e}\right]$ & $60 \mathrm{mH}$ \\
\hline \hline
\end{tabular}

Table 3: DC Cable, AC Network and Converter Parameters.

they are less likely to occur. On the other hand poleto-ground faults are less harmful but more likely to happen.

- It is necessary to isolate the pole-to-pole faults before the voltage across the DC link is reversed, or else the diodes of the two-level VSC station may be damaged.

- The fault position appears to have the same effect on both types of faults, i.e. fault peak and rate of change of current are both reduced with distance to fault. In particular for pole-to-pole faults this is clearly evident as the line impedance is the main current limiting factor. However, for pole-to-ground faults the fault resistance is considered as one of the main influencing elements so the impact of fault position cannot be pre-determined. Due to high dependency of the fault current response on both position and resistance of the fault, it is anticipated that using single indicator (e.g. current $d i / d t$ ) may not be sufficient to achieve discriminative protection.

- If the transformer has a delta winding arrangement on the converter side (as is the case here), the poleto-ground fault on the DC side causes the voltage of the other healthy pole to double (two times nominal value) if no voltage limiter circuit is employed.

- Pole-to-pole faults are easier to detect but much more challenging to isolate successfully as they require very fast disconnection, while pole-to-ground faults (especially high resistive faults) pose less of a threat to the inverters (longer disconnection could be permitted), but harder to detect/discriminate.

- Conventional VSC produces larger DC fault current due to discharging of a large DC link capacitor. The DC link voltage does not reverse due to the existence of the diode circuit.

The comprehensive fault characterisation presented in this paper will act as preliminary knowledge for the design of successful protection strategies in MT-HVDC systems, where a great challenge of faulty line discrimination rises. The investigation has already prompted some distinctive features $(d v / d t, d i / d t$, high frequency components and travelling wave effects) which are present in the obtained voltage and current waveforms. These results have given an initial indication that high speed discriminative DC protection scheme 
may need to be of hybrid nature, i.e. make use of more than one fault detecting principle. Further studies are needed to verify fault current characteristics in a multi-terminal DC system supplied from a number of inverters.

\section{Acknowledgements}

The authors would like to thank Alstom Grid Technology Centre, Stafford, UK, for their technical and financial support. Authors are grateful for being given the possibility to carry out this work.

\section{References}

[1] P. Bresesti, W. Kling, R. Hendriks, and R. Vailati, "HVDC connection of offshore wind farms to the transmission system," Energy Conversion, IEEE Transactions on, vol. 22, no. 1, pp. 37-43, 2007.

[2] N. Flourentzou, V. Agelidis, and G. Demetriades, "VSC-based HVDC power transmission systems: An overview," Power Electronics, IEEE Transactions on, vol. 24, no. 3, pp. 592-602, March 2009.

[3] J. Espi and J. Castello, "Wind turbine generation system with optimized dc-link design and control," Industrial Electronics, IEEE Transactions on, vol. 60, no. 3, pp. 919-929, 2013.

[4] T. Vrana., "Guide for the development of models for HVDC converters in a HVDC grid," in Cigre, WG:B4.57, Tech. Rep., 2014.

[5] W. Lu and B.-T. Ooi, "Optimal acquisition and aggregation of offshore wind power by multi-terminal voltage-source HVDC," Power Delivery, IEEE Transactions on, vol. 18, no. 1, pp. 201-206, 2003.

[6] D. V. Hertem and M. Ghandhari., "Multi-terminal VSC-HVDC for the european supergrid: Obstacles," Renewable and Sustainable Energy Reviews, vol. 14, no. 9, pp. 3156 - 3163, 2010.

[7] H. Ha and S. Subramanian, "Implementing the protection and control of future dc grids," Alstom Grid Technology Centre, Innovation and Technology Department, Jan 2015.

[8] F. G. A. Matthias K. Bucher, Roger Wiget and C. M. Franck., "Multiterminal HVDC networks? - What is the preferred topology?" Power Delivery, IEEE Transactions on, vol. 29, 2014.

[9] M. Bucher and C. Franck, "Fault current interruption in multi-terminal HVDC networks," Power Delivery, IEEE Transactions on, vol. PP, no. 99, pp. 1-1, 2015.

[10] C. Greiner, T. Langeland, J. Solvik, and O. Rui, "Availability evaluation of multi-terminal dc networks with dc circuit breakers," in PowerTech, IEEE Trondheim, 2011, pp. 1-8.

[11] C. Franck, "HVDC circuit breakers: A review identifying future research needs," Power Delivery, IEEE Transactions on, vol. 26, no. 2, pp. 998-1007, April 2011.

[12] M. Callavik, A. Blomberg, J. Hafner, and B. Jacobson, "The hybrid HVDC breaker," in ABB Grid Systems, November 2012.

[13] M. Hajian, D. Jovcic, and B. Wu, "Evaluation of semiconductor based methods for fault isolation on high voltage dc grids," Smart Grid, IEEE Transactions on, vol. 4, no. 2, pp. 1171-1179, June 2013.

[14] K. Sano and M. Takasaki, "A surgeless solid-state dc circuit breaker for voltage-source-converter-based hvdc systems," Industry Applications, IEEE Transactions on, vol. 50, no. 4, pp. 2690-2699, July 2014.

[15] C. Barker and R. Whitehouse, "An alternative approach to HVDC grid protection," in $A C$ and DC Power Transmission, 10th IET International Conference on, 2012, pp. 1-6.

[16] J. Hafner and B. Jacobson, "Proactive hybrid HVDC breakers - A key innovation for reliable HVDC grids," in Cigre Symp, Sep 2011, pp. 358-361.

[17] B. Xiang, Z. Liu, Y. Geng, and S. Yanabu, "DC circuit breaker using superconductor for current limiting," Applied Superconductivity, IEEE Transactions on, vol. 25, no. 2, pp. 1-7, April 2015.

[18] J. Yang, J. Fletcher, and J. O'Reilly, "Short-circuit and ground fault analyses and location in VSC-based DC network cables," Industrial Electronics, IEEE Tran. on, vol. 59, no. 10, pp. 3827-3837, Oct 2012.
[19] _ - "Multi-terminal dc wind farm collection and transmission system internal fault analysis," in Industrial Electronics, IEEE International Symposium on, July 2010, pp. 2437-2442.

[20] J. Rafferty, L. Xu, and D. Morrow, "DC fault analysis of VSC based multi-terminal HVDC systems," in AC and DC Power Transmission, 10th IET International Conference on, Dec 2012, pp. 1-6.

[21] J. Rafferty, L. Xu, and J. Morrow, "Analysis of voltage source converter-based high-voltage direct current under DC line-to-earth fault," Power Electronics, IET, vol. 8, no. 3, pp. 428-438, 2015.

[22] L. Tang and B.-T. Ooi, "Locating and isolating DC faults in multiterminal DC systems," Power Delivery, IEEE Transactions on, vol. 22, no. 3, pp. 1877-1884, July 2007.

[23] T. Worzyk, Submarine Power Cables: Design, Installation, Repair, Environmental Aspects. Springer, 2009.

[24] J. Candelaria and J.-D. Park, "VSC-HVDC system protection: A review of current methods," in Power Systems Conference and Exposition, IEEE/PES, March 2011, pp. 1-7.

[25] W. Leterme, P. Tielens, S. De Boeck, and D. Van Hertem, "Overview of grounding and configuration options for meshed HVDC grids," Power Delivery, IEEE Trans. on, vol. 29, no. 6, pp. 2467-2475, 2014.

[26] M. Bucher and C. Franck, "Analytic approximation of fault current contribution from AC networks to MTDC networks during pole-toground faults," Power Delivery, IEEE Transactions on, vol. PP, no. 99, pp. 1-1, 2015. 